\title{
Sorption of Coated and Uncoated Nanocrystalline Zinc Oxide from Aqueous Solutions onto Raw and Acetylated Cellulose Sago Hampas: Equilibrium, Kinetic and Thermodynamic Studies
}

\author{
E.K. Droepenu ${ }^{1, a}$, B.S. Wee ${ }^{2, b^{*}}$, S.F. Chin ${ }^{3, c}$, and K.Y. Kok ${ }^{4, d}$ \\ ${ }^{1,2,3}$ Resource Chemistry Program, Faculty of Resource Science and Technology, \\ Universiti Malaysia Sarawak 94300, Kota Samarahan, Sarawak, Malaysia. \\ ${ }^{1}$ Graduate School of Nuclear and Allied Sciences, University of Ghana, AE1, Kwabenya-Accra, \\ Ghana. \\ ${ }^{4}$ Malaysian Nuclear Agency, Bangi, Kajang, 43000 Selangor, Malaysia \\ akobladodzie01@yahoo.com, b*swboon@unimas.my, csfchin@unimas.my, \\ dkykok2020@gmail.com
}

Keywords: Raw sago hampas (RSH), acetylated sago hampas (ACSH), equilibrium isotherm, kinetic studies, thermodynamic studies, sorption efficiency.

\begin{abstract}
In this study, sorption efficiency of coated (C-) and uncoated (U-) zinc oxide nanoparticles (ZnO-NPs) in aqueous solution onto raw sago hampas (RSH) and acetylated sago hampas (ACSH) was studied. Physical and chemical characteristics of both the sorbate and sorbents were analysed using various characterization techniques. The mechanism of the sorption process was evaluated using equilibrium isotherms, kinetic and thermodynamic studies. From the study, maximum percentage removal of both sorbate ions were achieved at an equilibration time of 100 minutes with an optimum sorbate mass of $2.0 \mathrm{~g}$ per $50 \mathrm{ml}$. The study recorded a maximum $\%$ removal of $85.1 \%$ \& $87.6 \%$ for C- and U-ZnO-NPs $(<50 \mathrm{~nm})$ onto $\mathrm{RSH}$ and $90.0 \%$ \& 91.1\% onto ACSH. Langmuir isotherm fitted well for the sorption process with the highest efficiency of $0.793 \mathrm{mg} / \mathrm{g}$ recorded for C-ZnO-NPs onto RSH. Pseudo-second model best described the sorption process. An exothermic and non-spontaneous sorption process was realised in all the sorption studies except that of U-ZnO-NPs $(<50 \mathrm{~nm})$ onto ACSH which became spontaneous as temperature increased. Based on the findings from the multiple approaches employed, both sorbents could be proposed as viable alternatives to act as a green sorbent in the removal of $\mathrm{ZnO}-\mathrm{NPs}$ from water and wastewater.
\end{abstract}

\section{Introduction}

The high usage of nanoparticles (NPs) in various fields and its integration into commercial products and biomedical applications are as a result of their unique physicochemical characteristics [1, 2, 3, 4, 5]. The safety of these nano zinc oxide $(\mathrm{ZnO})$ particles remain a major threat of toxicity to biological systems $[1,6,7]$. Research shows that biological response to manufactured nanoparticles such as zinc oxide of nano sizes are often greater than the same product at micro sizes, particularly with regard to cytotoxic effects and lung tumours [8]. On the other hand, surface modification of nano zinc oxide particles using materials such as surfactants, polymers, or polyelectrolyte has proven to either mitigate or heighten the toxicity of ZnO-NPs as pristine was used as a case study [9]. However, various scientific techniques have been employed to restore environmental damage by these emerging pollutants to aquatic media. Outcome of some of these studies reported on major disadvantages such as high energy demand, incomplete removal and generation of large quantity of toxic waste sludge in all these conventional removal techniques [10].

Adsorption technique has been demonstrated to be an effective and attractive process in pollutant remediation due to its simple design, flexibility in operation and high efficiency $[11,12]$. Many biosorbent materials $[13,14]$ been used as adsorbents are readily available, inexpensive, and are a source of renewable lignocellulose biomass. Some of these materials undergo chemical modifications such as functionalization $[15,16,17,18,19]$ or grafting of nanoparticles on the other materials $[20,21]$ for efficient sorption of pollutants in aqueous solutions. 